\title{
Adult literacy practitioners and employability skills: resisting neoliberalism?
}

\begin{abstract}
We draw on theories of policy enactment to explore the ways in which the situated, material and external contexts and professional cultures in adult literacy in the UK have influenced practitioners. Our analysis of the transnational (OECD, EU) and UK external policy contexts found that skills-related education is prioritised, with a focus on economic growth through increased productivity and accountability. This can lead to a narrow conceptualisation of literacy as a set of information processing skills needed for employment that limits the curriculum so that the knowledge of the participants is ignored. However, our findings show that there is not a one-way flow from the transnational to the local. Instead, literacy practitioners translate and enact policy texts based on their situated contexts and professional cultures leading to approaches to teaching and learning that keep learners and their goals at the centre of the curriculum. We conclude that shared understandings of good practice and an underpinning value system, along with creative ways of delivering pre-set outcomes, allow practitioners to resist to some extent the neoliberal discourse whilst meeting the requirements of policy and funding. However, how feasible delivering this alternative curriculum is over the longer term remains to be seen.
\end{abstract}

Keywords: adult literacy; neoliberalism; Human Capital Theory; employability

\section{Introduction}

In this article, we draw on theories of policy enactment, the dual processes of policy interpretation and translation by a diverse range of policy actors across a wide variety of situations and practices (Ball, Maguire, and Braun, 2012, p. 21), to explore the ways in which the situated, material and external contexts and professional cultures in adult literacy in the UK have influenced practitioners. We begin by exploring the external context; in particular, how neoliberalism impacts at the transnational and national levels on adult literacy programmes. We conceptualise neoliberalism as a cultural, political and economic phenomenon premised on the idea of the 'self-regulating market' that operates efficiently and effectively. Under neoliberalism education systems have been mandated to develop efficient, creative and problem-solving learners and workers for a globallycompetitive economy leading to the neglect of education's social and developmental responsibilities (Olssen, 2009). These institutionalised practices have been partially accomplished by persuading each individual teacher and learner to treat the effects of neoliberalism as personal rather than structural and so the discourse can become accepted as normal rather than as in need of critique and transformation. A key way in which this happens is through is the use of a wealth of metrics to measure performativity that are centred on what is important for market considerations and what is accessible to measure, which does not necessarily reflect the core values of the work, that is, the quality of the teaching, inclusion and relationships (Lynch, 2006).

Our initial focus is on whether neoliberalism, and the human capital theory (HCT) that underpins it, has a negative impact on the adult literacy curriculum in the UK. Transnational and national policies that focus on promoting adult literacy skills such as those of the OECD, $(1997 ; 2012)$ and the Department for Business, Innovation and Skills (2014) consistently advocate the importance of the development of employability skills for the good of the economy but pay little attention to education's role in human flourishing. Yet, as researchers have pointed out, (for example, Raaper, 2017; Singh et al., 2014) global influence is not uni-directional because actors in national and local contexts can challenge and mediate its effects. We therefore examine the links between transnational and national policies and their enactment at the local level through research into the actions of adult literacy practitioners from two different projects: one in Scotland and the other in the North of England. We consider how professional cultures of more holistic approaches to teaching and learning interact with wider neoliberal policy forces. In order to set our research in 
context we begin with an analysis of HCT and its critics. We then show how the theory has been incorporated into policy at the transnational and national levels before moving on to discuss how these policies are enacted at the local level.

\section{Human Capital Theory}

HCT is the dominant theory that underpins claims about direct and causal links that are made between education systems and the economy in policy documents related to adult literacy (e.g. EUR-Lex, 2015; OECD, 2013; 2016). The theory was derived from research in the USA in the 1960s that showed that college graduates earned more than high school graduates and this implied that there was a financial return for the time and resources that had been dedicated to education and training. This led Schultz $(1960,571)$ to argue that, since college graduates earned more, education should be treated 'as an investment ...[and] since education becomes part of the person receiving it, I shall refer to it as human capital'. Human capital theory therefore proposes first, that differences in earnings can be causally connected to education and second, as a consequence, investing at a national level in the education system could be justified in the light of likely returns in the form of economic growth. Schultz (1962) justified this latter proposition by pointing out that, although tangible physical assets such as factories and equipment were important, nation states such as Japan and Germany that had invested in their education systems were more likely to experience economic growth through increased productivity than countries that did not invest. This argument, that increasing human knowledge leads to increases in worker productivity, is now used to justify investment in all forms of education but with the emphasis on the state as a facilitator, rather than a provider.

Becker $(1972,1975,2002)$ further developed HCT by both extending it to wider social activities such as those related to the family and also by focusing on the power of individual choice. His view was that human behaviour is based on the economic self-interest of individuals operating within freely competitive markets and education, therefore, was no longer to be viewed as 'consumption' but as investment (Blaug, 1976). These assumptions are reflected in Becker's definition of human capital as 'any stock of knowledge or characteristics the worker has (either innate or acquired) that contributes to his or her productivity' (Becker 1975, 16). This focus on productivity came at the expense of other forms of knowledge that lead to the development of an individual's potential, greater well-being and so on.

There have been a number of criticisms of HCT, especially of the version developed by Becker. The first critique is of the underpinning assumption that labour markets work rationally and efficiently that ignores the 'complex relationships between institutions, structures and individual agents that history, sociology, psychology, political economy and other disciplines explore' (Allais 2012,261). The second is that the theory reduces the person "merely to "human capital", not as a life to be lived, but as mere economic potential to be exploited' (Gillies 2011, 225). This means, as Foucault $(2008,226)$ argues, that instead of seeing workers as partners in any economic exchange they move to being 'an entrepreneur of the capitalist self', which is now seen as both the producer and also the source of earnings. Third, this individualistic focus opened up the possibility of being able to blame individuals for failing to invest in their own development rather than considering the economic and social circumstances in which they were living (Miller and Rose, 2008). Fourth, by focusing purely on the economic outcomes of education, little consideration is given to its social, equity and knowledge creation roles (Rubenson, 2015). Finally, Hall (2011) argued that the theory's emphasis on the individual and family as the basis for social organisation has led to a neglect of the collective and social welfare aspects of society. These critiques can be broadly summarised as refuting the assumption that the purpose of education is solely about the skills acquisition that drives economic growth. Instead critics argue that this view neglects education's important role in enabling human flourishing. 
Have the assumptions underpinning HCT, particularly those relating to the focus on skills acquisition, impacted on adult literacy education? In order to explore this we now turn to a review of the relevant transnational and national policies.

\section{Human capital discourses in transnational and national educational polices}

In this section, we explore the external context of policy enactment by first undertaking a brief review of the ways in which OECD, EU and UK policy documents have drawn on HCT to advocate for a concentration on improving literacy skills. We then outline how these policies have led to a particular conceptualisation of the literacy curriculum through neoliberal discourses of 'employability', which in turn has led to a focus on narrow skills rather than a holistic approach that develops a curriculum based on participants' own knowledge and interests.

Throughout its policy documents the $\operatorname{OECD}(1997 ; 2000 ; 2001 ; 2012 ; 2016)$ makes strong links between individual literacy skills and economic returns. For example:

For individuals, investment in human capital provides an economic return, increasing both employment rates and earnings. This can be demonstrated either by looking at education levels, or at more direct measures of human capital such as numeracy and literacy scores (OECD 2001, 3).

In addition, the claim is made that skills development is fundamental to global economic competitiveness. For example: 'OECD countries receive measurable and substantial positive economic returns as a result of strong literacy skills' (OECD 1997, 4). Moreover, these skills, it is claimed, are driven by individual endeavour and are a form of investment - 'skills have become the global currency of $21^{\text {st }}$ - century economies' (OECD 2012, 10).

This model of education asserts that large sections of the adult population need to be 'up-skilled' (OECD 2000,xiii) and leads to an assumption of the importance of skills-focused education. For example: 'without proper investment in skills, people languish on the margins of society, technological progress does not translate into economic growth, and countries can no longer compete in an increasingly knowledge-based global society' (OECD 2012,3). The human capital perspective also gets translated into narrow, measurable indicators such as those used in the Programme for the International Assessment of Adult Competencies (PIAAC) that aims to 'measure the key cognitive and workplace skills needed ... for economies to prosper' (OECD 2016, 1). This type of assessment has been criticised on the grounds that the test reflects adults' socio-demographic characteristics rather than their abilities to use literacy in a variety of contexts (Desjardins and Ederer, 2015; Hamilton, 2012).

In the European Union investment in human capital is also regarded as fundamental to adult literacy. For example, the EU emphasised that 'general levels of competence must increase, both to meet the needs of the labour market and to allow citizens to function well in today's society' (CEC $2006,3)$. This document also stated that the purpose of education and training was to increase 'the participation in the workforce of young people and extend that of older people' (ibid, 4). Later, it was suggested that education and training had a 'fundamental role to play in ... equipping citizens with the skills and competences which the European economy and European society need in order to remain competitive and innovative' (CEC, 2011a, 1). Whilst, in 2015, investment in education and training was advocated on the grounds that: 'it is money well spent. Good education and training help promote sustained economic growth, as well as sustainable development' (EUR-Lex 2015, 1).

As Hamilton $(2012,171)$ has argued, when the focus is on economic growth through increased 
productivity it means that 'formal learning is privileged over informal learning and standardised and measurable outcomes are preferred for demonstrating achievement' and this narrows the curriculum because the achievement of employability skills becomes the most important focus. Moreover, the powerful standards established through PIAAC (OECD, 2016) and the EU competence frameworks such as the 'Europe 2020' strategy (CEC, 2011b) become taken for granted, meaning that the focus of education is on the national productivity agendas that are in the interests of industry, often at the expense of the needs of other people who are treated as an investment rather than as social and cultural beings (Rizvi and Lingard, 2010). In addition, the narrow domains of skillsfocused knowledge perpetuated by these interests become accepted as normal and so are difficult to challenge (Gorur, 2014).

Policy documents in the UK similarly prioritise human capital outcomes in adult literacy programmes. For example, in Scotland a clear link is made between skills and productivity because: 'the skill level of the workforce is likely to impact significantly on the effectiveness of capital investment and the ability of employers to adopt innovative work practices' (Scottish Government $2007,13)$. Policy documents also lay the blame for the lack of skills on the individual because: 'if an individual has a weakness in [literacy] skills, they are less likely to make an effective contribution to Scotland's economy' (Scottish Government 2012, 1). Similarly, English policy highlights the role of adult literacy provision in improving 'economic and personal returns to [Government's] investment' (Department for Business, Innovation and Skills 2011, 11). The benefits of literacy development to the 'wider economy' are emphasised together with the suggestion that 'labour market engagement, i.e. work, is the biggest driver of skills development.' (Department for Business, Innovation and Skills, 2014 , 4). Adults with low literacy skills are more likely to be unemployed and also more likely to suffer from physical and mental health difficulties (Department for Business, Innovation and Skills. 2014). As a result, the unemployed and the 'inactive' were identified as a priority within literacy education policy, so that they can 'get into work and contribute to the economy' (ibid, 23).

This focus on employment led to the introduction of specific policies between 2010 and 2012 that were designed to ensure that claimants of welfare benefits made successful transitions into work. Staff at Jobcentre Plus, (a government-funded employment agency and social security office whose aim is to help people of working age find employment in the UK (Job Centre Guide, 2018) were responsible for implementing these changes. The first initiative (The Work Programme, DWP, 2011) was designed so that it could be delivered by private, public and voluntary sector organisations and aimed to support long-term unemployed people to find work. However, the only metric by which the success of these providers was judged was through job outcomes (i.e. transitions into jobs) and the financing model was of payment-by-results. The result of this was "black box" contracts ...[that provided] considerable uncertainty, variability and potential vulnerability as to the type, quality and intensity of interventions being delivered' (Carter and Whitworth 2017, 802). At no point in this policy is there any reference to the role of the unemployed participants in influencing either the nature of their support or the type of employment trajectory they are working towards. Yet other research (Taulbut et al. 2018, 15) found that a 'more substantive commitment to addressing personal circumstances which prevent people from gaining and remaining in employment (such as childcare and health problems) and ensuring a greater supply of job opportunities' was much more likely to lead to long-term employment.

In 2012 a new sanctions regime was introduced with financial penalties if recipients of 'Job Seekers Allowance' (JSA) (a benefit designed to support unemployed individuals with living expenses whilst looking for work administered by JobCentre Plus) did not demonstrate that they were actively looking for work. The stated purpose of this approach was to encourage JSA claimants to search harder for employment and to discourage them from leaving work through misconduct or without good cause (DWP, 2012). In addition, all existing claimants of out-of-work disability benefits were 
reassessed and those that were assessed as fit for work were then moved on to JSA. Research showed that the result of this reassessment process was 'a greater increase in adverse mental health outcomes' (Barr, Taylor-Robinson and Stuckler, 2016 343). So it appears that, although the explicit aim of these welfare reforms was to reduce dependency, it actually further marginalized the most vulnerable groups (ibid).

This combination of a focus on skills and the economy on the one hand, and reducing welfare expenditure on the other, is based on a 'work first' approach to employability 'where programmes focus mainly on compulsory job search and short-term interventions to facilitate a quick return to work' (Lindsay et al. 2007,539). Critics have argued that this approach means that the unemployed and inactive are encouraged to enter the labour market as quickly as possible, potentially by accepting low-paid or inappropriate jobs, and this, in turn, means that disadvantaged people are dealt with by using a standardised, short-term intervention model (Salisbury, 2004). In addition, the strong punitive elements of the sanctions were designed to increase the speed of return to the labour market and were not concerned about whether jobs were sustainable or led to improvements in participants' employability or health (Carter and Whitworth, 2017).

The impact of these changes had a number of negative consequences for literacy learners. First, since people with literacy difficulties are more likely to be long-term unemployed, the impact of the sanctions outlined above fell more heavily on them. Second, funding for literacy programmes in FE colleges, local authorities and the voluntary sector had all been reduced so most providers had to seek either alternative external funding or reduce provision and this reduced their flexibility. Third, changes in the welfare benefits meant that claimants needed increased literacy skills to apply for JSA because applications had to be made on-line so people that had had sufficient literacy to manage their daily lives were no longer able to cope. Finally those that did find a place on a programme were often given a curriculum that prioritised narrow employment-skills focused outcomes that neither respected learners' own goals nor valued their life experiences and this can have a negative impact on their learning (Tett, 2016).

Clearly then the impact of HCT on policies aimed at adult literacy learners had many negative impacts but, as Ball (2007) discusses, all policies have to be related to local practices. This means that there are always opportunities to disrupt and adapt by practitioners who may have different views of what is appropriate practice. This leads us to examine how employability-focused policies are enacted at the local level using research with experienced literacies practitioners on how their local and material contexts and professional cultures impacted on their perception of the opportunities and constraints offered through the current focus on employability.

\section{Methodology}

The data on which we draw are derived from two areas of the UK: Scotland's central belt and the North of England. The Scottish sample comprised twenty practitioners from community-based projects in Scotland's four major cities and six other local authority areas. In each of these areas a literacy practitioner and the person that had overall responsibility for literacies in that organisation was interviewed between September 2015 and May 2016. Experienced people were interviewed because this enabled them to be able to reflect on changes in policy and practice over time. Their experience ranged from 20 years of service to nearly 6 years with the median being 12 years. Each telephone interview lasted around an hour and focussed on how the opportunities and constraints of employability-focused programmes had influenced their approaches to learners.

The English sample involved teachers of adult literacy from a range of organisations, including colleges and training providers in the northern English counties of West and South Yorkshire. Between 2014 and 2016 seventeen structured telephone interviews of approximately twenty 
minutes were held with teachers with experience ranging from one to twenty years to identify their perceptions of literacy. Participants were asked to outline their teaching role and the nature of the organisations in which they work. The interview questions then focused on their views about why adults needed to be literate and on the abilities or qualities they felt a literate adult should have. They were also asked about the policies that influenced the adult literacy curriculum in their organisations. Additional semi-structured face-to-face interviews lasting between forty minutes and one hour were held with four of these practitioners who represented different contexts (further education colleges, local education authority and private training providers) to explore their views in greater depth. The relationship between literacy and employability and economic concerns was an emerging theme in both telephone and face-to-face interviews.

The interviews were recorded, transcribed and the transcriptions analysed thematically (Braun and Clarke, 2006) to allow for the probing of emerging issues. We first identified themes from the literature on teaching and learning in adult literacy (e.g. González et al., 2005; Tett et al., 2012; Smythe, 2015) and then set out to find instances of these approaches in the interview transcripts, paying attention to new themes that arose, and that were important to each of the cohorts as a whole. This means that in the analysis, each data-item was given equal attention in the coding process; themes were checked against each other and back to the literature. This method of analysis has the advantage of giving a holistic picture rather than a fragmented view of individual variables. The names used in the quotations are pseudonyms.

Inevitably there are limitations to the research. First, data were collected from practitioners who opted to take part so we were not interviewing a representative sample. Second, our sample is small but we are using the data from the practitioners to illustrate, rather than validate, our findings. Third, there is the possibility that practitioners were painting an overly rosy picture of their approach to the curriculum due to their commitment to being responsive to the students in their programmes. However, we had access to the curriculum documents for a number of the programmes and so were able to ascertain that what they told us in their interviews was consistent with their practice.

Table 1 lists the interviewees from the Scottish and English samples showing the type of organisations in which they work and their years of teaching experience.

Table: Interviewees' characteristics

\begin{tabular}{|l|l|l|l|}
\hline Name (pseudonym) & Location & Type of organisation & Years of experience \\
\hline Alan & Scotland & Homelessness NGO & 18 \\
\hline Ann & Scotland & $\begin{array}{l}\text { LA Community Learning } \\
\text { Service }\end{array}$ & 17 \\
\hline Brian & Scotland & $\begin{array}{l}\text { LA Community Learning } \\
\text { Service }\end{array}$ & 18 \\
\hline Callum & Scotland & $\begin{array}{l}\text { LA Community Learning } \\
\text { Service }\end{array}$ & 13 \\
\hline Carol & North of England & Further education college & 12 \\
\hline Catherine & North of England & Further education college & 1 \\
\hline Clare & North of England & Training provider & 4 \\
\hline David & Scotland & $\begin{array}{l}\text { LA Community Learning } \\
\text { Service }\end{array}$ & 7 \\
\hline Debbie & North of England & Further education college & 5 \\
\hline Denise & Scotland & $\begin{array}{l}\text { LA Community Learning } \\
\text { Service }\end{array}$ & 12 \\
\hline Donna & North of England & Adult education college & 11 \\
\hline
\end{tabular}




\begin{tabular}{|c|c|c|c|}
\hline Emma & Scotland & Family Learning NGO & 16 \\
\hline Faye & North of England & Training provider & 1 \\
\hline Felicity & North of England & Adult education college & 8 \\
\hline Garry & Scotland & Youth focussed NGO & 12 \\
\hline Heather & North of England & Further education college & 9 \\
\hline Jane & North of England & Training provider & 2 \\
\hline $\mathrm{Jim}$ & Scotland & Youth focussed NGO & 15 \\
\hline Jo & Scotland & $\begin{array}{l}\text { LA Community Learning } \\
\text { Service }\end{array}$ & 11 \\
\hline Joe & North of England & Training provider & 4 \\
\hline John & North of England & Training provider & 11 \\
\hline Judith & Scotland & $\begin{array}{l}\text { LA Community Learning } \\
\text { Service }\end{array}$ & 16 \\
\hline Karen & Scotland & $\begin{array}{l}\text { LA Community Learning } \\
\text { Service }\end{array}$ & 20 \\
\hline Kathy & Scotland & $\begin{array}{l}\text { LA Community Learning } \\
\text { Service }\end{array}$ & 10 \\
\hline Lorna & Scotland & $\begin{array}{l}\text { LA Community Learning } \\
\text { Service }\end{array}$ & 5.75 \\
\hline Louise & Scotland & $\begin{array}{l}\text { LA Community Learning } \\
\text { Service }\end{array}$ & 14 \\
\hline Lucy & North of England & Further education college & 20 \\
\hline Margaret & Scotland & $\begin{array}{l}\text { LA Community Learning } \\
\text { Service }\end{array}$ & 9 \\
\hline Mary & North of England & Training provider & 12 \\
\hline Moira & North of England & Further education college & 12 \\
\hline Pauline & North of England & Training provider & 20 \\
\hline Pete & Scotland & $\begin{array}{l}\text { Local Authority (LA) } \\
\text { Community Learning } \\
\text { Service }\end{array}$ & 17 \\
\hline Sarah & North of England & Training provider & 5 \\
\hline Sheila & Scotland & $\begin{array}{l}\text { LA Community Learning } \\
\text { Service }\end{array}$ & 19 \\
\hline Sian & Scotland & Family Learning NGO & 8 \\
\hline Sonia & North of England & Training provider & 1 \\
\hline Sue & Scotland & $\begin{array}{l}\text { LA Community Learning } \\
\text { Service }\end{array}$ & 20 \\
\hline
\end{tabular}

\section{Practitioners' views}

In this section, we show how policy was interpreted and translated at the local level. First, we examine the changes that practitioners have experienced in the outcomes expected from adult literacy programmes. We are prioritising outcome measurements because these externally imposed criteria privilege those aspects of performance which can be quantified and generally fail to recognize more qualitative, equally important changes (Salisbury, 2004). The consequence of this narrowing of the curriculum in response to these externally imposed outcomes tends to result in a deficit approach to learners' own knowledge (Tett, Hamilton and Crowther, 2012). Moreover, such outcomes are a manifestation of the growing distrust of frontline professionals' experience that can lead to an emphasis on what is easily measured, rather than what is important (Moutsios, 2010). 
We then move on to examine how practitioners have resisted the more negative impacts of the employability discourse on literacy learners. We follow Hollander and Einwohner (2004) in arguing that resistance has two central dimensions: action (physical, material or symbolic) and opposition in that actors challenge or subvert dominant discourses in some way. In terms of action our data shows that practitioners focused mainly on the material by providing more resources for the literacy programmes and on the symbolic by drawing on participants' knowledge and expertise in the curriculum. Opposition to dominant discourses was mainly through subversion of the employability discourse through delivering a learner-focused curriculum. Whilst we agree with Hollander and Einwohner (2004) that resistance needs to be intentional, we consider that some actions, such as when practitioners avoid using reporting mechanisms that they consider unfair to the people they work with, may actually be hidden from the view of powerful authorities. We suggest, however, that this type of resistance is still intentional because it results in specific changes in how the literacy curriculum is delivered. Drawing on this broad definition of resistance then enables us to consider both how policy is interpreted in ways that lead to shared understandings between practitioners as well as how 'the dynamics of context shape policy enactments' (Ball, Maguire, and Braun 2012, 20).

Although practitioners from Scotland and England were working in somewhat different contexts they were all responding to the changes in welfare benefits that were implemented across the UK. So we report on these changes in the outcomes they were expected to deliver mainly using examples from both samples. Where they differ, as in the local authority literacy services in Scotland, we detail the different possibilities available. There were more differences in the types of resistance that could be offered so in that section we first report separately on the options that could be used by the Scottish and English samples and then combine their responses when the strategies were similar.

\section{Outcomes}

All the respondents reported that there had been changes in the outcomes they were expected to deliver that impacted on how they organised and approached literacy programmes. These changes were mainly caused by the 'work first' approach to employability: for example, 'I teach Functional Skills and the main aim is to get our students ready for the world of work' (Debbie). A number of participants explained how the employability agenda was shaping their organisations' curriculum offer, with one practitioner describing it as the 'key driver' (Sarah). Another referred to employability as 'forcing our hand to look at ways of doing things' (John). It was also exacerbated by a reduction in welfare benefit levels and both these factors caused a decline in the motivation of learners that were now participating. One teacher from the English sample felt the change in learners' motivation particularly keenly:

The mandated job centre - that policy has had a massive effect on us... suddenly we were having people who were being forced to come ... and it feels completely different ... almost like a crowd control type of situation because they are quite forth right in putting across how little they want to be there. (Joe)

One group of changes was driven by the requirement for claimants to apply on-line for employmentrelated benefits that led to: 'huge pressure on Jobseekers that have to use digital skills to actively seek employment' (Emma). The result was a more constrained curriculum 'targeted at employability skills' (Alan) where 'a lot of our workshops are based on getting people to see how to write an email for a job and how to write a letter, how to write a job advert' (Faye). Some practitioners felt that this narrow curriculum arose from a lack of belief by other professionals in the possibility of improvement in learners' capabilities and so resulted in 'inward thinking along the lines of developing a CV, job search, digital skills etc.' (Pete) rather than a belief that people would change 
and grow if given the right opportunities.

Another issue was capturing employability outcomes especially where official criteria for success were numbers moving on to other courses, or gaining a qualification or employment. This was because many participants 'were far away from the job market and although many gained "soft skills" such as increased confidence they could not be accredited and were not easy to record' (Sue). Some funders required very prescriptive skills-focused content in literacy courses that led to learners gaining accreditation and the result of this was negative. For example, 'there are fewer opportunities for learners to develop more personal interests that usually enable them to be more engaged in learning' (David). 'There's not really much room in terms of our funding and our policy for having people who just come along because they want to learn a bit' (Jane). 'Obviously for people to get on the right course and to achieve is all important but I think there is perhaps a more learner-focused developmental approach that I think may be lost in the drive to improve performance in the target driven culture.' (Lucy).

The outcomes that could be achieved had to be thought through carefully because: 'for the work with young people we get an initial starting payment but if they don't complete a training course or move on to a positive destination then we get nothing' (Brian).

Instead of learners themselves applying to join literacy programmes many were now referred from JobCentre Plus because they were 'having trouble claiming benefits and ... filling in online all the [employment related] stuff - CVs, evidence of applying for jobs and so on' (Sarah). Consequently, large numbers of people that hadn't accessed literacy services before were coming along and that meant some interviewees were 'able to offer a greater range of courses in response to the learners, many of who see employability as their key goal' (Callum). Many practitioners reported that they were now 'attracting greater numbers of learners' (Sian) but one worried that 'we aren't as focused on the people that are more difficult to reach because of the demand from those that are more aware of the opportunities we offer' (Judith).

Although increasing learner participation was welcomed, it could also be problematic. This was particularly true for people with mental health issues who had been on long-term benefits because they now had 'to apply for jobs and this is adding to their stress and their ill health' (Denise). In terms of meeting employment-related outcomes this group of learners could be more demanding and this led to 'quite a lot of buck passing by the other sectors [such as further education and private providers] especially when individuals have mental health issues' (Margaret). There was a particular impact from private providers because they 'tend to cherry pick those learners nearest to achieving the specified outcomes so we can end up supporting the learners that are further away from being employment ready' (Sheila). The result of this could be 'that learners, particularly the longer-term unemployed ... are pushed from pillar to post, from agency to agency, where boxes are ticked and statistics are generated to justify funding' (Jim).

An awareness of the different needs of this new group of learners had led a number of local authority literacy services in Scotland to set up systems so that they could be more appropriately taught and supported. For example: 'we have been providing training to our front-line staff ... on how anti-social behaviour issues can be effectively defused ... and also awareness-raising sessions so that they can be more sympathetic to people in very distressed states' (Karen). Others were working more closely with colleagues including 'financial services staff who do sessions in libraries to help with benefits' (Ann). Finally, a number had 'established [services] that enable staff to understand what services they should refer learners onto' (Brian). 
Such support can be seen as one step on the way to implementing a more learner-centred focus and in the next section we explore how the practitioners sought to avoid a 'teaching curriculum' (Lave and Wenger, 1991) that focuses on the programmatic priorities and goals of the funder and is based on the view that knowledge is always mediated through the instructor.

\section{Resisting the employability skills agenda}

At the heart of the Scottish practitioners' resistance to a narrow interpretation of the literacy curriculum was being clear about their professional values. So for nearly all of the interviewees good practice meant: 'ensuring that the learners' goals are at the centre of our provision' (Kathy). A key value was 'being focused on the assets that learners' bring rather than their deficits' (Joe) and many practitioners showed how they operationalized these values. For example, Gary said: 'rather than writing CVs we build the curriculum around what the young people are interested in. That means that they do develop their literacy skills but in ways that arise from their own interests'. Many operated from 'a funds of knowledge' approach (González et al., 2005); Alan, working in a project for homeless people, started off by:

Asking them about their housing issues or how they have dealt with social work so that we can use their experience. We get to deliver our outputs about being 'employment ready' but we start from their knowledge rather than telling them what to do and it's so much more effective.

Sian, who was based in a family learning project, argued that she was able to 'work from the strengths of our learners ...from what the parents know and we ask them to share their knowledge with each other. She considered that 'it's about changing attitudes...learning how to see themselves positively again'. From her perspective participants growing self-confidence was as important as their gaining literacy skills.

Rather than seeing knowledge as an economic commodity many of the interviewees were focused on knowledge as a way of expressing critical opinions about the world. For example:

We discuss why they think they didn't get qualifications when they were at school and what they think could be done about it in ways ... that put the emphasis back on the system failures. They then write about how they might change education and this helps to build up their skills as well as improving their self-esteem. This means we can hit our output targets but in a way that enables us to still stick to our social practices approach (Louise).

Louise was able to work in this way because she ensured that the writing, talking and listening skills that were developed through these discussions then enabled participants to write more effective $\mathrm{CVs}$, improve their interview skills and gain greater confidence.

For most practitioners, good practice also involved taking time to remove barriers to help people towards becoming more employable. This meant that: 'although our overall aim is to move young people on to positive destinations, behind that is helping them to take small steps...so they gain the confidence in what they know' (Jim).

Working in these ways was not easy because of the time and commitment involved. In particular staff were under pressure from JobCentre Plus to report on learners' attendance but 'we have made it clear that any referrals they make to our provision is on the basis that we will not monitor or report on learners' attendance because it would violate our principles' (Ann). Practitioners were helped to stick to their value base because of the: 'passion for the job that gives you the courage to work in this way because all your experience tells you that this is the right kind of approach that is 
going to help people to learn' (Emma). The practitioners also had the support of colleagues that they considered 'shared their values' and so they trusted them 'to make good judgements' (Sian). However, there was still 'a big discrepancy between the rhetoric about the value of our work and the lack of funding for it at the local authority level' (Brian) due to the pressures on Council budgets from the services such as school education that they were required to provide.

In the English sample, participants also experienced constraints and frustration related to 'the pressures of achievement and funding' (Mary) and the requirement for end examinations linked to course funding conflicted with their personal and professional values. 'When I first started delivering here we were able to put on courses that would help people to grow in their confidence and in themselves. It ... [gave you more flexibility] if you didn't have an end formal exam' (Pauline). Another interviewee described how she incorporated literature and creative writing into her literacy classes so that 'It's not just about an exam ... I feel we're in danger of losing the love of literature, the love of writing ...[now] we are having to just drill it in' (Felicity). One of the literacy teachers involved in the follow-up interviews had changed her role in the time between the telephone interview and the face-to-face meeting and she explained how her frustration at the restricted view of literacy resulting from funding constraints and assessment processes at her previous organisation had inspired her to leave her job and work freelance, offering literacy classes she believed were more tailored to learners' individual needs and interests and developed their literacy through creative writing, project work and reading poetry and fiction. 'Literacy is not just about filling in a form' (Sarah). All these practitioners questioned the constraining effects of the employability agenda on the adult literacy curriculum. 'Should people be trained up just to do the jobs they do?' (Donna).

Some practitioners resisted the constraints of an employability-focused curriculum by celebrating the progress of their learners in non-work based contexts. The ways in which learners use their literacy to support their children with schoolwork, for instance, was a commonly recurring theme in the North of England interviews, as was their ability to become more actively involved in their communities as a result of their literacy development. One participant was particularly proud of her learners' achievements, one of whom had gained so much confidence from attending her classes that she had begun volunteering as a 'Reading Friend' at her child's school, listening to the pupils reading and giving them encouragement. Another learner from the class had recently had some of her creative writing published in the local newspaper (Sarah).

A number of interviewees from both samples had found more creative ways of delivering outcomes including making 'use of impact statements from learners that include gains in self-confidence that are powerful ways of explaining the whole life impact that they experience' (Ann). Staff also had to be careful about how they described their provision as one pointed out: 'I was anxious we might lose our family learning provision, so I pitched this as parental engagement for employability ... Crucially, this still allows us to deliver some of the initial work that is so valuable' (Karen). Another interviewee described how within her organisation some of the courses offered had to be titled 'Communication for Employment' rather than 'English' or 'Literacy'; 'It's jargon basically to get the funding.' (Sonia). The various ways in which these literacy practitioners operated to translate and enact policy texts (Ball, Maguire, and Braun, 2012) were through what Smythe (2015) has called 'workarounds'; situations in which literacy educators seize, rather than seek, discretion when 'policies are seen to be unworkable in practice, or in conflict with professional and philosophical values' (ibid, 6).

For some participants resisting the employability agenda meant recognising that learners had different reasons for attending literacy classes:

I don't think it's just about work actually. A lot of people come here because they have to. Sometimes pressure from the Job Centre and so on ... but for some people in the class their 
reasons for coming are very different. I think it's more about being amongst people who are in a similar position to them socially, as well as to do with being literate and about gaining confidence generally through developing these skills, particularly in speaking and listening. It empowers them. They might then feel more able to go out into the wider world whether it's to get a job or progress on to a college course ... I'm not sure that when they joined the class that that could have been their aspiration originally (Sarah).

When applying for funding staff had to be clear about what could be achieved. This meant that it had to be thought through carefully so that it did not compromise 'the values about what good practice should look like' (Lorna). They looked for funders that were more flexible about outcomes and one found that: ' $\mathrm{X}$ organisation] is just looking for any improvement in literacies or English as a second language (ESOL) communication skills or digital skills [rather than] having to demonstrate that people can write a CV ... or that they have moved on to accredited courses' (Pete). For some external funding had made it possible to develop more 'critical literacy' programmes that 'developed communication and numeracy skills at the same time as involving the participants fully' (Sue). However, such temporary funding could generate a huge administrative burden that 'took skilled staff away from the "front line" and meant that their ability to innovate was lost' (Sue).

\section{Discussion and Conclusion}

In this article we have added to the literature and theory on policy enactment (Ball, Maguire, and Braun, 2012) because we have shown how the external context of neoliberalism, and the underpinning $\mathrm{HC}$ theory, mediates the situated and material contexts and professional cultures in adult literacy at the local level. We have also shown how theories of resistance (Hollander and Einwohner, 2004) contribute to an understanding of the boundaries within which professional cultures operate so that they can disrupt the ways in which policy becomes 'a part of the practice, perception and self-crafting of teachers' (Perryman, Ball, Braun and Maguire, 2017). Our research demonstrates that teachers/practitioners can challenge processes of educational reform through various forms of agentic resistance. In addition, we have brought a new dimension to research on the impact of neoliberalism because of our focus on the under-researched area of adult literacy education.

In summary, we have argued that the neoliberal discourse, with its emphasis on economic competitiveness through increased productivity and accountability (Olssen, 2009), has led to transnational and national policy documents that promote the importance of employability skills in literacy programmes. This is because the focus is on outcomes that are expected to lead to participants becoming more employable and such outcomes are based on narrowly focused skills rather than on the wider social and political benefits of literacy. This approach is reinforced by the international competencies of the OECD as well as the 'closer inter-institutional collaboration between the EU and the OECD' (Milana 2014, 102), because these competencies lead to accountability regimes based on outcome measurements that focus on employment. The assumption underpinning these regimes, we suggest, is that work of any kind is the solution to reducing poverty despite a great deal of evidence to the contrary (e.g. Rubenson, 2015; Scottish Government Social Research, 2015).

Policies that focus only on the economic, limit the curriculum at the national and local level in ways that ignore the knowledge of learners and so emphasises their limitations rather than their expertise (Tett et al, 2012). Through the focus on the individual and their responsibility for improving their economic worth, the dominant discourse means that people are required 'to be skilled, mobile, selfreliant, economic agents and notions of their "potential" and "fulfilment" are centred on their economic value' (Gillies and Mifsud 2016, 829). Thus the impact of broader social and economic inequalities on access to educational opportunities is obscured and the many ways in which large- 
scale systematic injustice is constructed out of individual differences are ignored (Connell, 2012). We have argued that this can lead to a narrow conceptualisation of the purpose of literacy education as the provider of 'employment ready' workers rather than as a means of contributing to human flourishing. This approach to literacy is then translated into a curriculum that is focused on delivering the information-processing skills claimed to be necessary for employment and the outcomes of gaining employment, qualifications or other work-related experience.

Yet, as Raaper $(2017,436)$ has pointed out, 'there is no linear flow from the global influence to the local, but national and local contexts can challenge and alter the global patterns of influence' and this led to our exploration of the links between transnational and national policies and their enactment at the local level. Our findings have shown how professional cultures of more holistic approaches to teaching and learning, expressed as a commitment to putting learners at the centre of the curriculum, have interacted with wider neoliberal policy forces. Despite the stress on performativity and the emphasis on 'results' in terms of measured outputs of learners' employment destinations, the professional culture of literacy practitioners that is open and responsive to learners has come into play. This shared understanding of good practice, and clear views of the underpinning value system, has enabled staff to assert their agency to support literacy that is based in rich and meaningful practices. The curriculum they have offered has instead been based on a 'funds of knowledge' approach (González, Moll and Amanti, 2005), which other research has suggested (e.g. Tett, 2016), can help learners to develop the effective strategies and skills they already use rather than being seen as having individual deficits that need to be corrected. As we have shown, the values that drove the practitioners' pedagogical practices was a focus on the learners' goals and so the learning arose out of 'the inherently socially negotiated character of meaning ... in, with, and arising from the socially and culturally structured world' (Lave and Wenger 1991, 51). The practitioners also emphasised the importance of using the individual's wider experience and operated from the position that the learners' experiences were a positive resource and thus they used a 'learning curriculum that evolves out of participation in a specific community of practice' (Lave and Wenger 1991, 97). This was based on an epistemology that acknowledges that knowledge is developed socially and this approach also enabled the 'development of criteria for deciding which knowledge is most worthwhile' (Allais 2012, 266).

Additionally, we have illustrated the ways in which practitioners use 'workarounds' in relation to the creative ways used to deliver pre-set outcomes and construct an open curriculum as well as making funding applications designed to enable more critical literacy focused programmes. These actions not only show how practitioners participate in policy networks as powerful actors but also enable them to 'draw attention to dissonances between policy discourses and the actualities of learning in local settings' (Smythe 2015, 6). These shared understandings of what is 'good practice' were developed through interactions with colleagues that reinforced a collective understanding of what were fundamental principles for delivering literacy programmes.

As Ball notes, "policies are always incomplete in so far as they relate to or map onto the "wild profusion of local practice"' $(1994,10)$. We have illustrated this local practice, through showing the complex ways in which official policies are translated and enacted within and across a range of literacy programmes. In conducting this research we were consistently shown not only the courage of practitioners in confronting the inevitability of employability skills focused programmes but also their willingness to actively try to implement a different set of ideas about literacy education. The spaces that the practitioners found in which to continue to work in the ways that they valued have enabled them to develop 'a politics of solidarity based on empathy and committed engagement' with learners (Shaw 2018, 26). They have been helped in taking this stand by the strengths they derive from being part of a long tradition of literacy work that places the learner at its centre (Hamilton and Tett, 2012). Yet working in these created and creative spaces comes at a cost in 
terms of the effort that has to be made in simultaneously respecting the learners' own knowledges and satisfying the requirements of funders in delivering the outcomes that they expect. Such costs are placed unfairly on the shoulders of these practitioners who face an on-going struggle to work in the ways they value. Will these practitioners be able to resist the neoliberal discourse over the long term? We have witnessed their resourcefulness in finding creative solutions so we can only share Gramsci's $(1971,395)$ commitment to being 'a pessimist because of intelligence, but an optimist because of will'.

\section{References}

Allais, S. 2012. "Economics Imperialism', Education Policy and Educational Theory." Journal of Education Policy 27 (2): 253-274. doi:10.1080/02680939.2011.602428.

Ball, S. J. 1994. Education Reform: A Critical and Post-structuralist Approach, Buckingham: Routledge. Ball, S. J. 2007. "Big Policies/Small World. An Introduction to International Perspectives in Education Policy." In RoutledgeFalmer Reader in Education Policy and Politics, edited by B. Lingard and J. Ozga, 36-48. London: Routledge

Ball, S. J., M. Maguire, and A. Braun. 2012. How Schools Do Policy: Policy Enactments in Secondary Schools. New York: Routledge.

Barr, B., D. Taylor- Robinson and D. Stuckler et al. 2016. "Fit for Work or Fit for Employment? Does the Reassessment of Disability Benefit Claimants Using a Tougher Work Capability Assessment Help People into Work?" Journal of Epidemiol Community Health 70 (5): 339-345.

Becker, G. 2002. "The Age of Human Capital". In Education in the 21st Century, edited by E. Lazear, 38. Stanford CA: Hoover Institution Press.

Becker, G. 1972. "Schooling and Inequality from Generation to Generation Inequality: Comment." Journal of Political Economy 80 (3): S252-S255.

Becker, G. 1975. Human Capital: A Theoretical and Empirical Analysis. 2nd ed. New York: Columbia University Press.

Blaug, M. 1976. "The Empirical Status of Human Capital Theory: A Slightly Jaundiced Survey." Journal of Economic Literature 14 (3): 827-855.

Braun, V., and V. Clarke. 2006. "Using Thematic Analysis in Psychology." Qualitative Research in Psychology 3 (2): 77-101.

Carter, E. and A. Whitworth. 2017. "Work Activation Regimes and Well-being of Unemployed People: Rhetoric, Risk and Reality of Quasi-marketization in the UK Work Programme." Social Policy and Administration 51 (5): 796-816.

CEC (Commission of the European Communities). 2006. Adult Learning: It is Never Too Late to Learn, Brussels: Directorate General for Education, Training and Youth.

CEC. 2011a. Council Resolution on a Renewed European Agenda for Adult Learning (2011/C 372/01) http://eurlex.europa.eu/LexUriServ/LexUriServ.do?uri=CELEX:32011G1220\%2801\%29:EN:PDF.

CEC. 2011b. Council Conclusions on the Role of Education and Training in the Implementation of the 'Europe 2020' Strategy (2011/C70/01), http://eurlex.europa.eu/LexUriServ/LexUriServ.do?uri=OJ:C:2011:070:0001:0003:EN:PDF. Connell, R. 2012. "Just Education." Journal of Education Policy 27 (5): 681-683 doi: 10.1080/02680939.2012.710022.

Department for Business, Innovation and Skills. 2011. New Challenges, New Chances: Next Steps in Implementing the Further Education Reform Programme. London: BIS.

Department for Business, Innovation and Skills. 2014. Adult Literacy and Numeracy: Government Response to the House of Commons Business, Innovation and Skills Select Committee. Fifth Report of Session. 2014-15. London: BIS.

Desjardins, R. and P. Ederer. 2015 "Socio-demographic and Practice-oriented Factors Related to Proficiency in Problem Solving: a Lifelong Learning Perspective." International Journal of Lifelong Education 34 (4): 468-486.

Department of Work and Pensions 2011. The Work Programme, available at: 
https://www.gov.uk/government/uploads/system/uploads/attachment data/file/49884/the-workprogramme.pdf.

Department of Work and Pension 2012. Explanatory memorandum to the Jobseeker's Allowance (Sanctions) (Amendment) Regulations 2012 No. 2568, available at:

webarchive.nationalarchives.gov.uk/20130128102031/http://www.dwp.gov.uk/docs/jsa-sanctionsdraft-regs-2012-memorandum.pdf

EUR-Lex. 2015. New Priorities for European Cooperation in Education and Training (2015/C 417/04) http://eur-lex.europa.eu/legalcontent/EN/TXT/?uri=uriserv\%3AOJ.C_.2015.417.01.0025.01.ENG. Foucault, M. 2008. The Birth of Biopolitics: Lectures at the Collège De France 1978-1979. Translated by Graham Burchell. Basingstoke: Palgrave Macmillan.

Gillies, D. 2011. State Education as High-yield Investment: Human Capital Theory in European Policy Discourse. Journal of Pedagogy, 2 (2): 224-245.

Gillies, D. and D. Mifsud. 2016. "Policy in Transition: The Emergence of Tackling Early School Leaving (ESL) as EU Policy Priority." Journal of Education Policy 31 (6): 819-832 doi:

10.1080/02680939.2016.1196393.

González, N., L. Moll, and C. Amanti. 2005. Funds of Knowledge: Theorizing Practices in Households, Communities, and Classrooms. New Jersey: Lawrence Erlbaum Associates.

Gorur, R. 2014. "Towards a Sociology of Measurement in Education Policy." European Educational Research Journal 13 (1): 58-72.

Gramsci, A. 1971. Selections from the Prison Notebooks. London: Lawrence and Wishart

Hall, S. 2011. "The Neo-liberal Revolution." Cultural Studies 25 (6): 705-728. doi:

10.1080/09502386.2011.619886.

Hamilton, M. 2012. "The Effects of the Literacy Policy Environment on Local Sites of Learning." Language and Education 26 (2): 169-182.

Hamilton, M. and L. Tett, 2012. "More Powerful Literacies: the Policy Context." in More Powerful Literacies, edited by L. Tett, M. Hamilton, and J. Crowther, 31-57. Leicester: NIACE.

Hollander J. and R. Einwohner. 2004 "Conceptualizing Resistance." Sociological Forum 19 (4): 533 554.

Job Centre Guide 2018. What is the Job Centre Plus? https://www.jobcentreguide.co.uk/jobcentreplus-guide/4/what-is-the-jobcentre-plus

Lave, J., and E. Wenger. 1991. Situated Learning: Legitimate Peripheral Participation. Cambridge: Cambridge University Press.

Lindsay, C., R. McQuaid, and M. Dutton. 2007. "New Approaches to Employability in the UK:

Combining Human Capital Development and Work First Strategies?" Journal of Social Policy 36: 539560. doi:10.1017/S0047279407001171.

Lynch, K. 2006. "Neo-liberalism and Marketisation: The Implications for Higher Education." European Educational Research Journal 5 (1): 1-17.

Milana, M. 2014. "European Adult and Lifelong Education in Times of Crisis: Where is Social Justice when the Social Dimension turns into Social Cohesion?" CIVITAS EDUCATIONIS III (2): 89-105.

Miller, P., and N. Rose. 2008. Governing the Present: Administering Economic, Social and Personal Life. Malden, MA: Polity Press.

Moutsios, S. 2010. "Power, Politics and Transnational Policy-making in Education." Globalisation, Societies and Education 8 (1): 121-141.

OECD (Organisation for Economic Co-operation and Development). 1997. Literacy Skills for the Knowledge Society. Paris: OECD

OECD 2000. Literacy in the Information Age: Final Report of the International Adult Literacy Survey.

Paris: OECD

OECD. 2001. The Well-being of Nations: The Role of Human and Social Capital. Paris: OECD

OECD. 2012. Better Skills, Better Lives: A Strategic Approach to Skills Policies. Paris: OECD 
OECD. 2013 OECD Skills Outlook 2013: First Results from the Survey of Adult Skills

http://www.oecd.org/site/piaac/Skills\%20volume\%201\%20\%28eng\%29--full\%20v8-eBook\%20\%2801\%2010\%202013\%29.pdf.

OECD. 2016. The Survey of Adult Skills: Reader's Companion.2nd ed. OECD Skills Studies, OECD

Publishing: Paris http://dx.doi.org/10.1787/9789264258075-en.

Olssen, M. 2009. "Neoliberalism, Education, and the Rise of a Global Common Good." In Re-Reading Education Policy: A Handbook Studying the Policy Agenda of the 21st Century, edited by M. Simons, M. Olssen, and M. A. Peters, 433-457. Rotterdam: Sense Publishers.

Perryman, J. Ball, S. J., Braun A. and Maguire, M. 2017. "Translating policy: governmentality and the reflective teacher." Journal of Education Policy 32 (6): 1464-5106.

doi:10.1080/02680939.2016.1257160.

Raaper, R. 2017. "Tracing Assessment Policy Discourses in Neoliberalised Higher Education Settings." Journal of Education Policy 32 (3): 322-339. doi:10.1080/02680939.2016.1257160.

Rizvi, F. and B. Lingard. 2010. Globalizing Education Policy. Abingdon: Routledge.

Rubenson, S. 2015. "Framing the Adult Learning and Education Policy Discourse: The Role of the OECD." in Global Perspectives on Adult Education and Learning Policy, edited by M. Milana and T. Nesbit, 179-193. Basingstoke: Palgrave Macmillan.

Salisbury, J. 2004. "Clients, Claimants or Learners? Exploring the Joined-up Working of New Deal for 18-24 Year Olds." Journal of Education Policy 19 (1): 81-104. doi:10.1080/0268093042000182645. Scottish Government. 2012. Improve the Skill Profile of the Nation: Scotland Performs. Edinburgh: Scottish Government.

Scottish Government. 2007. Scottish Budget Spending Review. Edinburgh: Scottish Government. Scottish Government Social Research. 2015. What Do We Know About In-work Poverty? A Summary of the Evidence. Edinburgh: Scottish Government Social Research.

http://www.gov.scot/Publications/2015/01/3233/downloads\#res468484.

Schultz, T. 1960. "Capital Formation by Education. " Journal of Political Economy 68 (6): 571-583. Schultz, T. 1962. "Reflections on Investment in Man." Journal of Political Economy 70 (6): 1-8. Shaw, M. 2018. "Community Development: Reviving Critical Agency in Times of Crisis." in The Routledge Handbook of Community Development, edited by R. Phillips, S. Kenny, and B. McGrath, 26-39 Routledge: London.

Singh, P., S. Heimans and K. Glasswell. 2014. "Policy Enactment, Context and Performativity: Ontological Politics and Researching Australian National Partnership Policies." Journal of Education Policy, 29 (6): 826-844, DOI: 10.1080/02680939.2014.891763.

Smythe, S. 2015. "Ten Years of Adult Literacy Policy and Practice in Canada: Literacy Policy Tensions and Workarounds." Language and Literacy 17 (2): 4-21.

Taulbut, M., D. F. Mackay and G. McCartney. 2018. "Job Seeker's Allowance (JSA) Benefit Sanctions and Labour Market Outcomes in Britain, 2001-2014." Cambridge Journal of Economics 2018: 1-18 doi:10.1093/cje/bex088

Tett, L. 2016. "Learning, Literacy and Identity: I Don't Think I'm a Failure Anymore." British Journal of Sociology of Education 37 (3): 427-444. doi: 10.1080/01425692.2014.939265.

Tett, L., M. Hamilton, and J. Crowther. 2012. eds. More Powerful Literacies. Leicester: NIACE. 